\title{
Phylogeography and Molecular Species Delimitation of Pratylenchus capsici n. sp., a New Root-Lesion Nematode in Israel on Pepper (Capsicum annuum)
}

\author{
Xue Qing, ${ }^{1}$ Wim Bert,2 Abraham Gamliel, ${ }^{3}$ Patricia Bucki, ${ }^{1}$ Svetlana Duvrinin, ${ }^{4}$ Tamar Alon, ${ }^{4}$ and Sigal Braun Miyara1, + \\ ${ }^{1}$ Department of Entomology, Nematology and Chemistry Units, Agricultural Research Organization (ARO), The Volcani Center, Bet Dagan \\ 50250, Israel; ${ }^{2}$ Nematology Research Unit, Department of Biology, Ghent University, K. L. Ledeganckstraat 35, 9000 Ghent, Belgium; \\ ${ }^{3}$ Laboratory for Pest Management Research, Institute of Agricultural Engineering, ARO, The Volcani Center; and ${ }^{4}$ Extension Service \\ (Shaham); Israel Ministry of Agriculture \& Rural Development, Israel \\ Accepted for publication 7 November 2018.
}

\begin{abstract}
Root-lesion nematodes of the genus Pratylenchus parasitize the roots of numerous plants and can cause severe damage and yield loss. Here, we report on a new species, Pratylenchus capsici n. sp., from the Arava rift, Israel, which was characterized by integrative methods, including detailed morphology, molecular phylogeny, population genetics, and phylogeography. This species is widely spread across the Arava rift, causing significant infection in pepper (Capsicum annuum) roots and

analysis suggests that contemporary gene flow is prevented among different agricultural farms, while population dispersal from weeds (Chenopodium album and Sonchus oleraceus) to pepper occurs on a relatively small scale. Our results suggest that weeds are an important reservoir for the dispersal of $P$. capsici $\mathrm{n}$. sp., either as the original nematode source or at least in maintaining the population between growing seasons.
\end{abstract} inhibiting plant growth. Both morphological and molecular species delimitation support the recovered species as a new species. We found high cytochrome oxidase subunit I haplotype diversity, and phylogeography
Keywords: Arava rift, Capsicum annuum, Nematoda, new species, pepper, Pratylenchus, Tylenchomorpha
Root-lesion nematodes of the genus Pratylenchus are migratory endoparasites belonging to the family Pratylenchidae (Nematoda, Tylenchomorpha), with 100 species currently recognized (Geraert 2013; Hodda et al. 2014; Palomares-Rius et al. 2014; Wang et al. 2015). Pratylenchus spp. are considered to be the third most economically important plant-parasitic nematodes (Castillo and Vovlas 2007), causing yield losses of up to $85 \%$ of expected production (Nicol et al. 2011). Such losses can be even higher when nematodes interact synergistically with certain soilborne plant pathogens (Jones and Fosu-Nyarko 2014). Hence, detection and identification of Pratylenchus spp. is important. However, the taxonomical status and diagnosis of Pratylenchus spp. is often problematic. Past studies have been limited by their reliance on a small set of morphological traits or a few molecular barcoding genes (Hodda et al. 2014; Palomares-Rius et al. 2014; Singh et al. 2018; Wang et al. 2015), with no incorporation of historical phylogeography or underlying genetic variation. Although these types of data may be useful diagnostic implements, they can be deficient in species boundary delimitation given their high intraspecific variability, including variation of molecular barcodes (Castillo and Vovlas 2007; De Luca et al. 2011; Janssen et al. 2017; Roman and Hirschmann 1969; Tarte and Mai 1976). Consequently, an integrative approach, incorporating unbiased molecular delimitation methods, is needed for an accurate description of Pratylenchus spp.

The Arava rift is part of the Syrian African rift, located in the southeastern part of Israel and stretching from the Dead Sea to the Red Sea. It is an arid region characterized by an extremely harsh

${ }^{\dagger}$ Corresponding author: S. Braun Miyara; E-mail: sigalhor@volcani.agri.gov.il

Funding: This work was supported by the Chief Scientist of the Ministry of Agriculture and Rural Development, grant number 20-07-0012.

The author(s) declare no conflict of interest.

(C) 2019 The American Phytopathological Society environment, with a hot climate and high water salinity (PenMouratov et al. 2010). Agriculture in this region consists of intensive indoor production in net houses supported by drip irrigation and fertilization to provide adequate conditions for crop production. Over the past 50 years, the Arava rift has evolved into a unique agroecosystem with advanced agricultural technologies, producing highly profitable fresh vegetables, herbs, and cut flowers, mainly for export. However, in recent years, severe root infections caused by a root-lesion nematode have been detected in pepper from several agricultural farms in the Arava rift, suggesting a highly specialized nematode-plant interaction. Moreover, management of this nematode has not been successful. Hence, questions have been raised as to the identity and origin of this nematode, considering two major aspects: first, plant-parasitic nematodes are generally well managed in other regions in Israel; second, the Arava region is remote and isolated from other agricultural areas. Therefore, the objectives of the present study were to (i) characterize and formally describe this species by integrative approaches, (ii) employ different sequence-based delimitation methods to objectively interpret species boundaries, and (iii) trace the possible origin and transmission pathway to facilitate further management.

\section{MATERIALS AND METHODS}

Sampling and isolation of nematode specimens. Nine samples were collected between November 2017 and April 2018 from Israel's Arava rift region. Seven samples were taken from the root zone soil of pepper (Capsicum annuum) at the following farms: Ein Tamar (ET), Hatzeva (HZ), Ein Yahav (Ein Yahav pepper, EYP), Tsofar-B (TB), Tsofar-A (TA), Tsofar-East (TE), and Paran (PR). Two root-zone soil samples from weeds (Chenopodium album and Sonchus oleraceus) in Ein Yahav (Ein Yahav weeds [EYW]) were taken from the same nethouse as EYP. Additional samples of Pratylenchus mediterraneus were collected from alfalfa in Shefaa, Israel. Nematodes were extracted using a Baermann funnel. 
Morphological analyses. Extracted fresh nematodes were fixed in $4 \%$ formalin solution at $65^{\circ} \mathrm{C}$. Fixed specimens were rinsed several times with deionized water and gradually transferred to anhydrous glycerine for permanent slides (Sohlenius and Sandor
1987). Morphological characteristics of nematodes were observed with a Nikon Eclipse Ni light microscope and photographed using Nikon DS-Ri2 (Nikon Corporation, Tokyo, Japan) equipped with differential interference contrast. To visualize the nematode
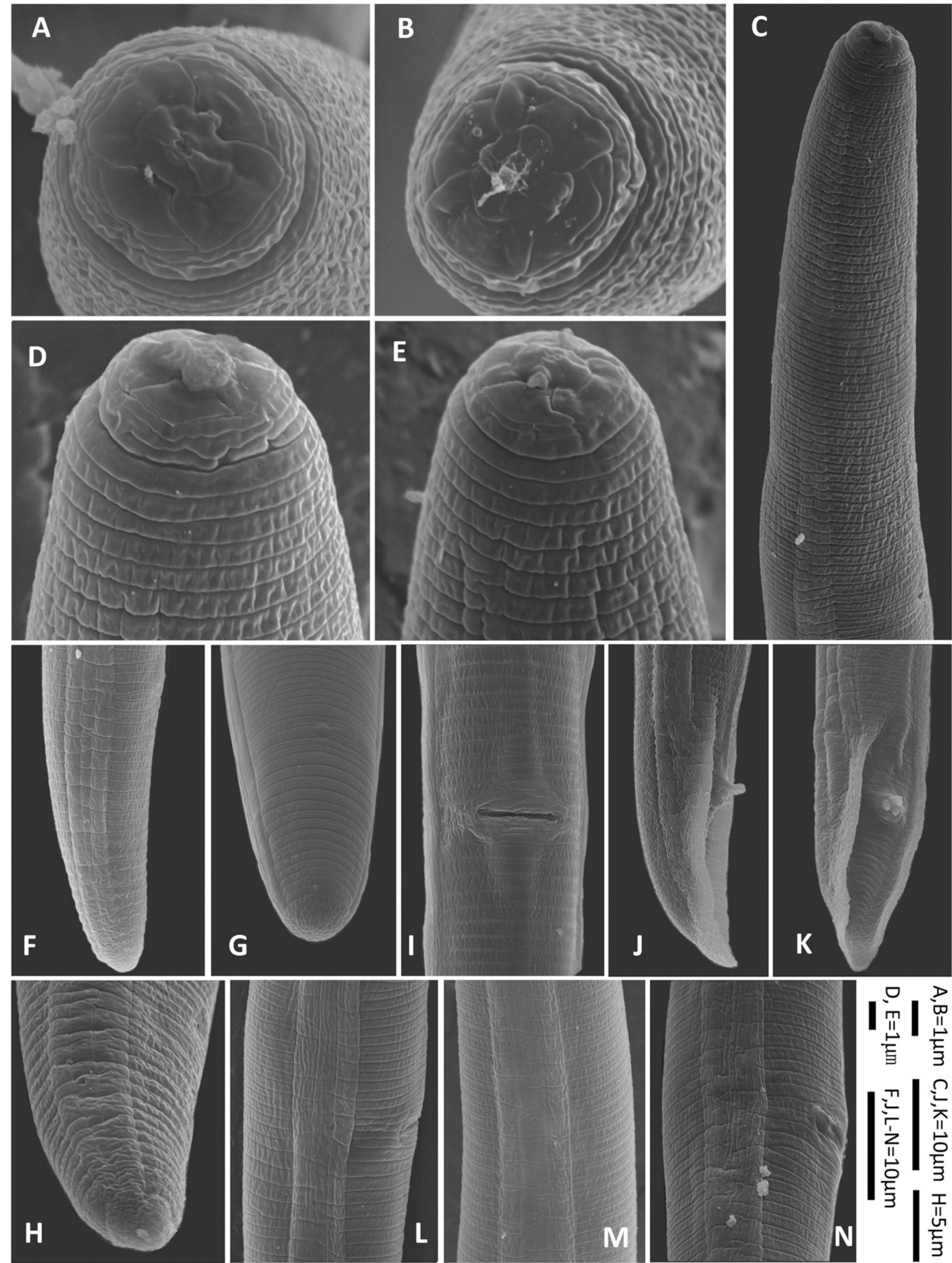

Fig. 1. Scanning electron microscopy photographs of Pratylenchus capsici n. sp. A, B, D, and $\mathbf{E}$, female en face view; $\mathbf{C}$, female anterior end; F, G, and $\mathbf{H}$, female tail; I, vulva region; $\mathbf{J}$ and $\mathbf{K}$, male tail region; and $\mathbf{L}$ to $\mathbf{N}$, lateral field. 
infection, root tissues were rinsed with water and then stained with acid fuchsin following the protocol of Bybd et al. (1983). Illustrations were prepared based on light microscopy drawings using Adobe Illustrator CS3.

For scanning electron microscopy (SEM) observation, samples of live specimens were heated in a microwave in Trump's fixative ( $2 \%$ paraformaldehyde $+2.5 \%$ glutaraldehyde in 0.1 M Sorensen's buffer) for a few seconds. The nematodes were then rinsed three times in double-distilled water and dehydrated through a series of gradient ethanol solutions (30, 50, 75, and 95\%, 20 min each) and, finally, three times in pure ethanol (10 min each). Thereafter, the rinsed nematodes were critical point dried with liquid $\mathrm{CO}_{2}$, mounted on stubs with carbon discs, and coated with gold $(25 \mathrm{~nm})$. The fixed nematodes were then observed through a

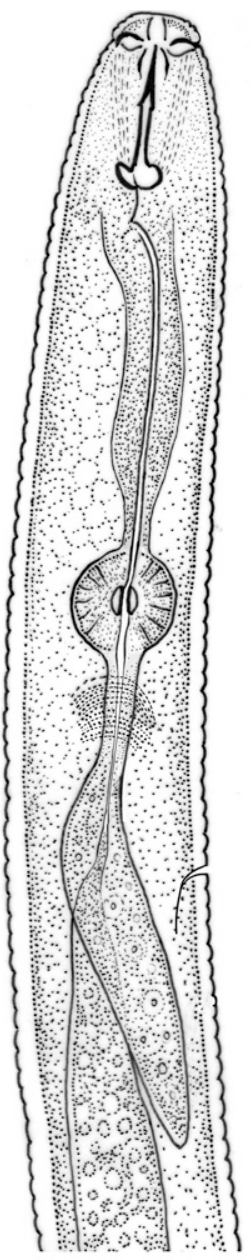

A
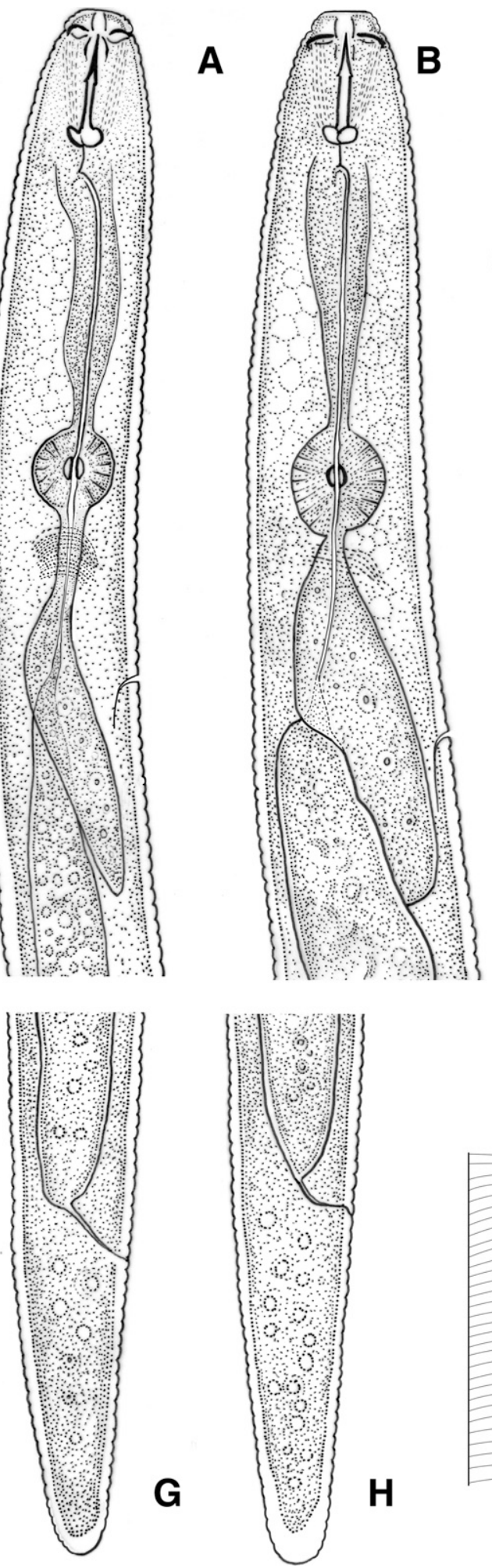
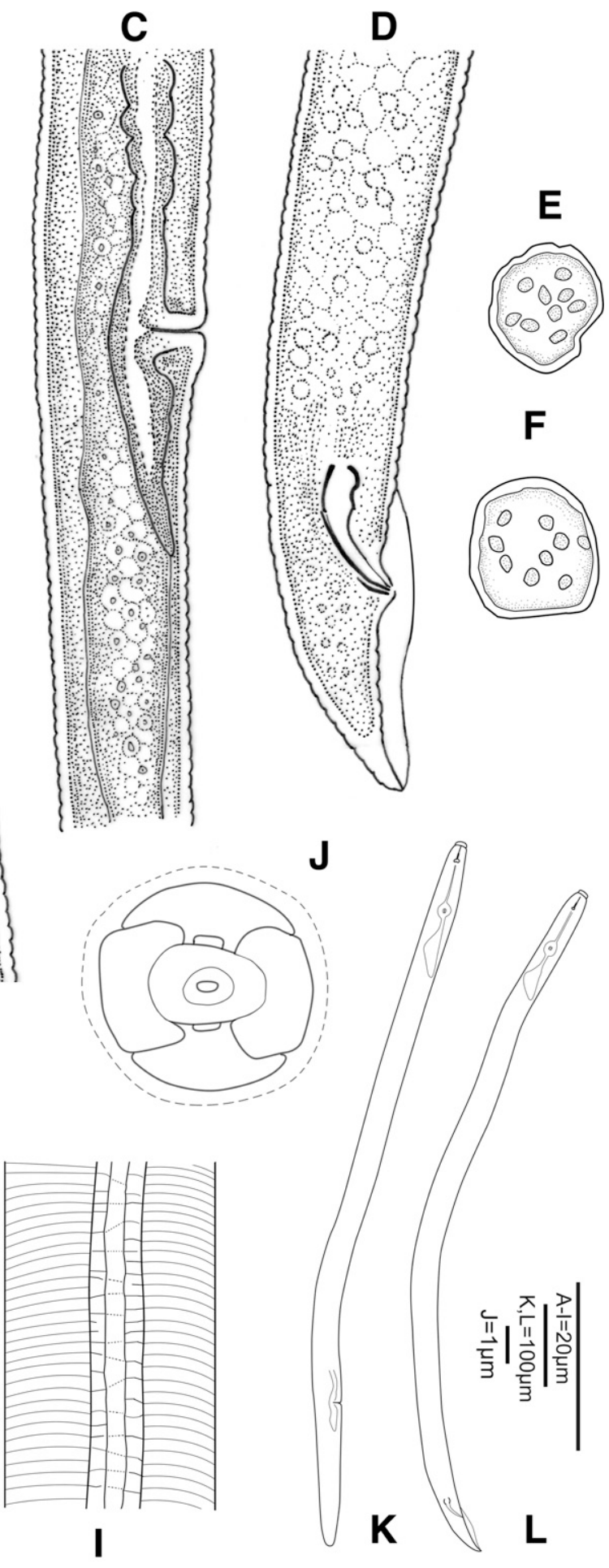

Fig. 2. Line drawing of Pratylenchus capsici sp. n. A and B, female anterior body region; C, vulva; D, male reproductive system showing the spicule, gubernaculum, and bursa; $\mathbf{E}$ and $\mathbf{F}$, spermatheca; $\mathbf{G}$ and $\mathbf{H}$, tail; $\mathbf{I}$, female lateral region showing lateral lines; J, lip region; K, female body habitus; and $\mathbf{L}$, male body habitus. 
microscope before observation in a JSM-840 electron microscope (Jeol, Tokyo, Japan) at $15 \mathrm{kV}$.

Molecular analyses. DNA was extracted from living nematode samples. Briefly, single individuals were transferred separately to a polymerase chain reaction (PCR) tube containing $10 \mu \mathrm{l}$ of $0.05 \mathrm{~N}$ $\mathrm{NaOH}$ solution and $1 \mu \mathrm{l}$ of $4.5 \%$ (wt/vol) Tween 20 . The tubes were incubated for $15 \mathrm{~min}$ at $95^{\circ} \mathrm{C}$; then, $40 \mu$ of double-distilled water was added to each sample. The $18 \mathrm{~S}$ ribosomal RNA (rRNA) gene

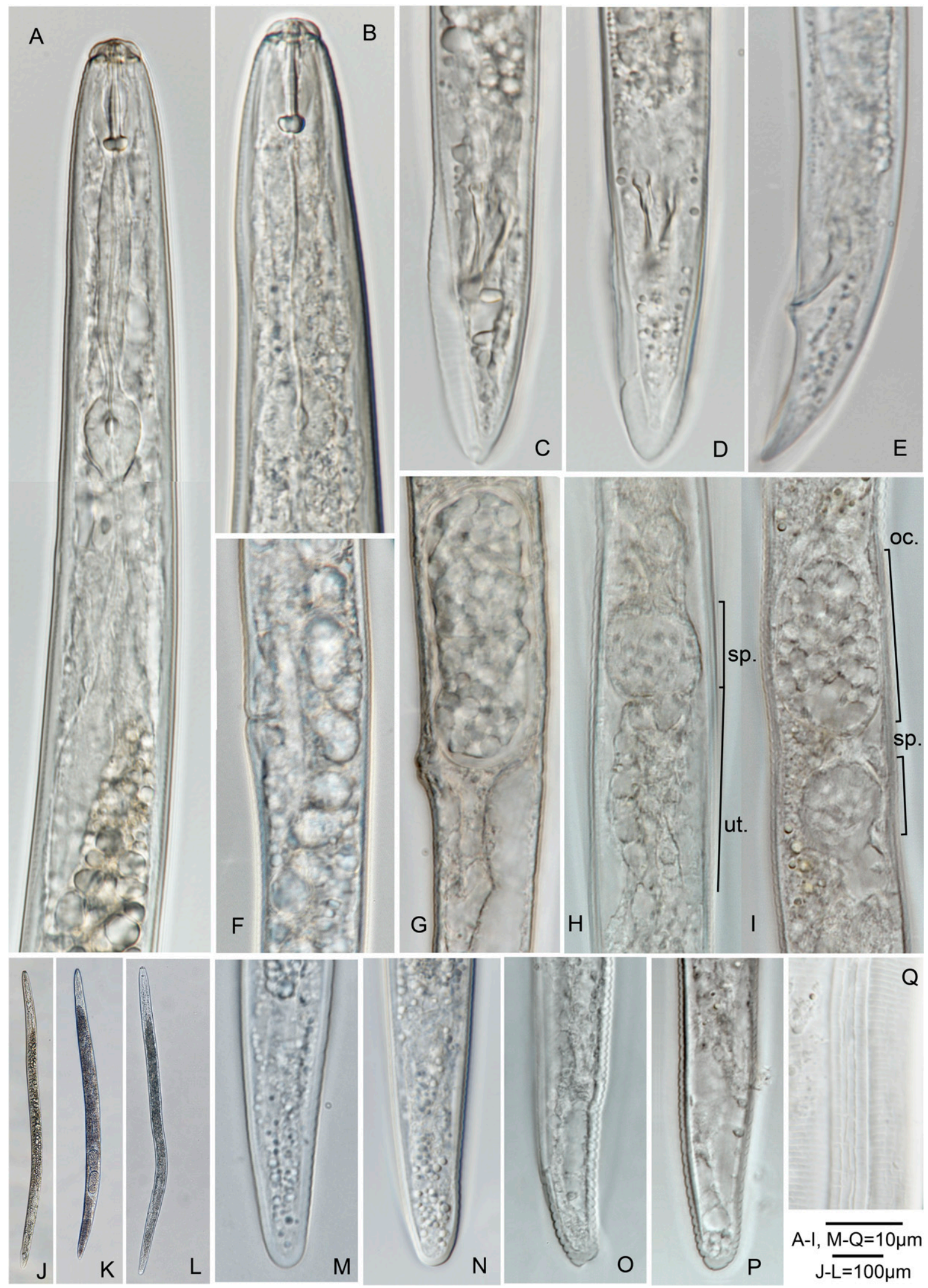

Fig. 3. Photomicrographs of Pratylenchus capsici n. sp. A and $\mathbf{B}$, female anterior body; $\mathbf{C}$ to $\mathbf{E}$, male tail; $\mathbf{F}$, vulva region of nongravid female; $\mathbf{G}$, vulva region of gravid female, showing the egg; $\mathbf{H}$, spermatheca (sp.) and uterus (ut.); I, oocytes (oc.) and spermatheca (sp.); $\mathbf{J}$ to $\mathbf{L}$, female body habitus; $\mathbf{M}$ to $\mathbf{P}$, female tail; and Q, lateral field. 
(18S) was amplified using the primers G18S4 (5'-GCT TGT CTC AAA GAT TAA GCC-3') and 18P (5'-TGA TCC WKC YGC AGG TTC AC-3') (Blaxter et al. 1998). The D2D3 domain of 28S rDNA (28S) was amplified using D2A (5'-ACA AGT ACC GTG AGG GAA AGT TG-3') and D3B (5'-TCG GAA GGA ACC AGC TAC TA-3') (Nadler et al. 1999). The internal transcribed rRNA gene spacer (ITS) was amplified using VRAIN2 F (5'-CTT TGT ACA CAC CGC CCG TCG CT-3') and VRAIN2 R (5'-TTT CAC TCG CCG TTA CTA AGG GAA TC-3') (Vrain et al. 1992). The cytochrome c oxidase subunit 1 (COI) gene fragment was amplified using JB3 (5'-TTT TTT GGG CAT CCT GAG GTT TAT-3') and JB4.5 (5' -TAA AGA AAG AAC ATA ATG AAA ATG-3') (Bowles et al. 1992). The PCR products were cloned (except for COI) using pGEM-T easy vector systems (Promega, Madison, WI) and subsequently sequenced in two primer directions at Hy-labs (Rehovot, Israel). Contigs were assembled using Geneious R6.1.8. The resulting sequences were deposited in the GenBank database under accession numbers MH796905 to MH796906, MH796969 to MH796980, and MH798799 to MH798802.

DNA sequences representing $P$. capsici n. sp. were analyzed together with other Pratylenchus sequences from GenBank. Multiple alignments for rRNA genes were built using the G-INS-i algorithm of MAFFT v. 7.205 (Katoh and Standley 2013) and the COI gene was aligned using TranslatorX (Abascal et al. 2010) under the invertebrate mitochondrial genetic code. For phylogeny reconstruction, the best-fitting substitution model was estimated using the Akaike Information Criterion in jModelTest v. 2.1.2 (Darriba et al. 2012). Maximum-likelihood (ML) and Bayesian inference (BI) analyses were performed on the CIPRES Science Gateway (Miller et al. 2010) using RAxML 8.1.11 (Stamatakis et al. 2008) and MrBayes 3.2.3 (Ronquist et al. 2012), respectively. ML analysis included 1,000 bootstrap (BS) replicates under the GTRCAT model whereas BI used the GTR+I+G model with four independent chains for $1 \times 10^{7}$ generations in two runs. For BI, Markov chains were sampled every 100 generations and $25 \%$ of the converged runs were discarded as burn-ins.

Species delimitation. Molecular species-delimitation analyses were performed using the generalized mixed-yule coalescent (GMYC) method (Pons et al. 2006), a Bayesian implementation of the Poisson tree processes (bPTP) method (Zhang et al. 2013), and the automatic barcode gap discovery (ABGD) method (Puillandre et al. 2012). Duplicated haplotypes and outgroup sequences were pruned from the dataset prior to analysis. The GMYC speciesdelimitation method was performed in the R package Splits (Ezard et al. 2009) with a single threshold. An ultrametric tree was constructed using BEAST v1.8.4 (Drummond et al. 2012). Default prior distributions were used except for the uncorrelated lognormal relaxed clock, and a constant size coalescent prior and uniform prior for ucld.mean parameter. Analyses were run for $1 \times 10^{8}$ generations, saving trees every $1 \times 10^{4}$ generations. The final output was examined visually in Tracer 1.7 (Rambaut et al. 2018) to determine whether the run had reached convergence (ESS values $>200)$. The

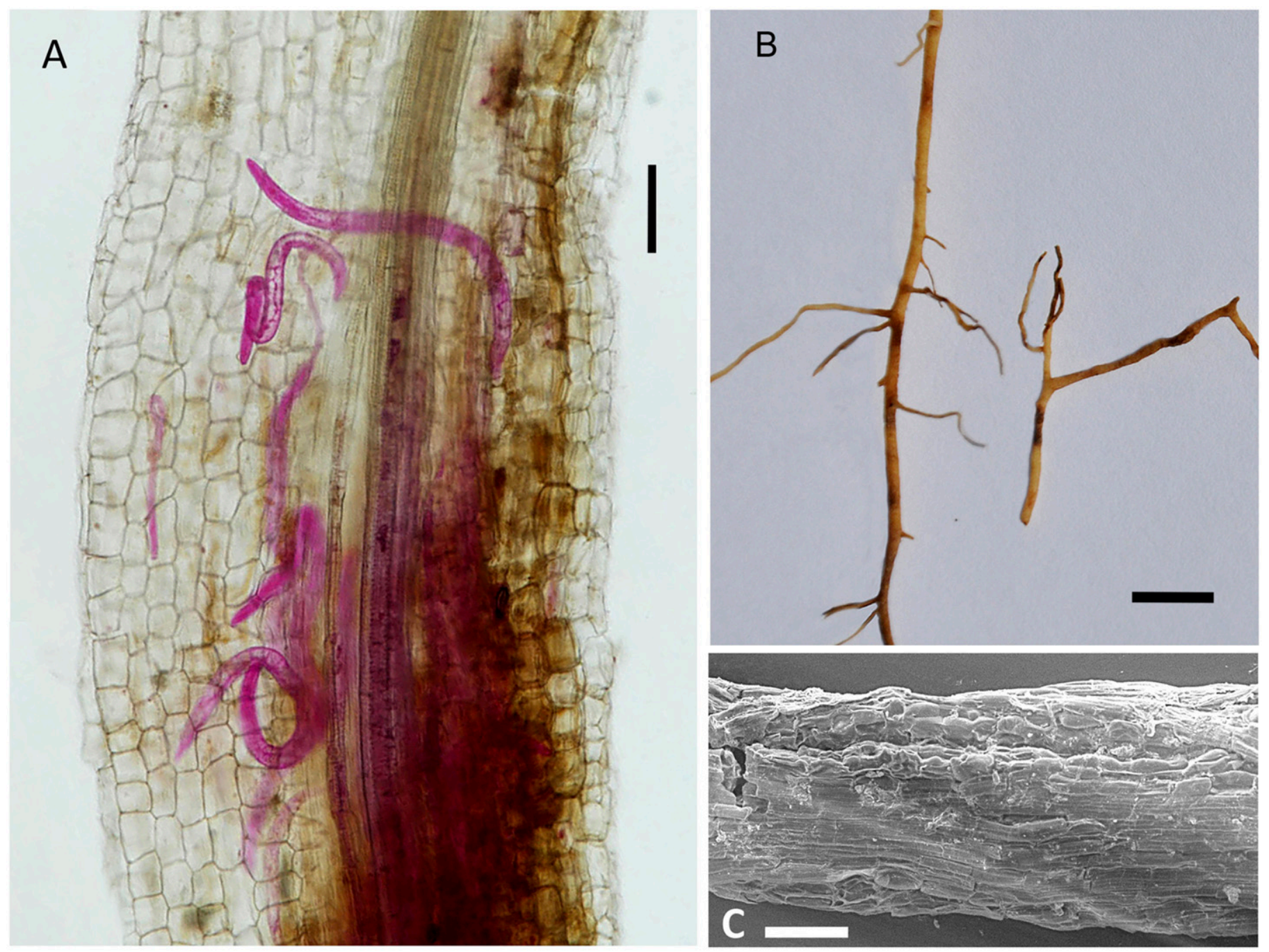

Fig. 4. Symptoms caused by Pratylenchus capsici n. sp. A, Fuchsin staining of nematodes infected root; B, infected root showing lesions; and $\mathbf{C}$, scanning electron microscopy photograph of root-lesion. Scale bar: $A=100 \mu \mathrm{m}, \mathrm{B}=8 \mathrm{~mm}$, and $\mathrm{C}=600 \mu \mathrm{m}$. 
TABLE 1. Morphometrics of population of Pratylenchus capsici n. sp. from the type location Tsofar, Israel ${ }^{\mathrm{a}}$

\begin{tabular}{|c|c|c|c|}
\hline \multirow[b]{2}{*}{ Characteristic } & \multirow{2}{*}{$\frac{\text { Holotype }}{\text { Female }}$} & \multicolumn{2}{|c|}{ Paratypes } \\
\hline & & Male & Female \\
\hline $\mathrm{n}$ & 1 (fixed) & 5 (fixed) & 15 (fixed) \\
\hline $\mathrm{a}$ & 26.7 & $30.6 \pm 3.97(25.2-34.9)$ & $26.7 \pm 2.21(22.3-30.1)$ \\
\hline $\mathrm{b}$ & 6.53 & $6.65 \pm 0.54(6.12-7.47)$ & $6.89 \pm 0.66(5.26-8.11)$ \\
\hline$b^{\prime}$ & 4.96 & $4.90 \pm 0.19(4.56-5.07)$ & $5.26 \pm 0.42(4.19-5.78)$ \\
\hline $\mathrm{c}$ & 18.8 & $21.5 \pm 3.07(18.5-26.1)$ & $20.5 \pm 2.31(17.3-24.3)$ \\
\hline$c^{\prime}$ & 2.58 & $2.42 \pm 0.62(1.90-3.30)$ & $2.45 \pm 0.33(1.92-3.11)$ \\
\hline $\mathrm{V}$ & 78.2 & $\ldots$ & $78.3 \pm 3.04(70.1-81.4)$ \\
\hline $\mathrm{O}$ & 20.8 & $18.6 \pm 2.36(15.2-20.4)$ & $20.8 \pm 3.19(15.3-27.1)$ \\
\hline $\mathrm{L}$ & 620 & $567 \pm 28.7(530-598)$ & $606 \pm 22.1(559-642)$ \\
\hline Anterior end to vulva & 485 & $\ldots$ & $474 \pm 18.7(446-498)$ \\
\hline Tail length & 33.0 & $26.9 \pm 4.53(20.3-32.3)$ & $29.9 \pm 4.29(24.4-37.0)$ \\
\hline Pharyngeal overlap & 30.1 & $30.3 \pm 4.68(26.5-38.0)$ & $27.1 \pm 4.86(18.8-33.0)$ \\
\hline Pharynx & 125 & $116 \pm 6.96(106-123)$ & $115 \pm 9.71(108-142)$ \\
\hline Cone of stylet & 6.85 & $6.86 \pm 0.88(5.93-7.2)$ & $6.95 \pm 0.36(6.57-7.31)$ \\
\hline Stylet length & 14.4 & $14.3 \pm 0.94(12.9-15.1)$ & $14.5 \pm 0.47(13.7-15.3)$ \\
\hline DGO from stylet base & 3.00 & $2.72 \pm 0.29(2.30-2.98)$ & $3.02 \pm 0.44(2.1-3.8)$ \\
\hline Anterior end to central of metacorpus & 58 & $56.1 \pm 3.49(52.2-61.0)$ & $54.4 \pm 3.81(49.1-63.8)$ \\
\hline Postuterine sac & 26.2 & $\ldots$ & $30.2 \pm 4.50(21.8-37.9)$ \\
\hline Anus/cloacal width & 12.8 & $11.5 \pm 1.76(9.80-13.9)$ & $12.2 \pm 0.70(11.2-13.8)$ \\
\hline Lip width & 7.85 & $7.44 \pm 0.53(6.9-8.1)$ & $8.25 \pm 0.53(7.5-9.49)$ \\
\hline Maximum body diameter & 23.2 & $18.8 \pm 2.65(15.2-21.9)$ & $22.8 \pm 2.16(20.1-27.2)$ \\
\hline Anterior end to nerve ring & 73.5 & $76.5 \pm 5.56(69.0-82.0)$ & $75.3 \pm 6.73(65.3-89.2)$ \\
\hline Anterior end to excretory pore & 70.6 & $77.7 \pm 10.3(70.4-85.5)$ & $86.9 \pm 8.31(72.8-97.4)$ \\
\hline Spicule length & $\ldots$ & $16.2 \pm 0.89(15.1-17.3)$ & $\ldots$ \\
\hline Gubernaculum length & $\ldots$ & $4.45 \pm 0.55(3.80-5.26)$ & $\ldots$ \\
\hline
\end{tabular}

a All measurements are in micrometers and are presented as mean \pm standard deviation (range). DGO = dorsal pharyngeal gland orifice.

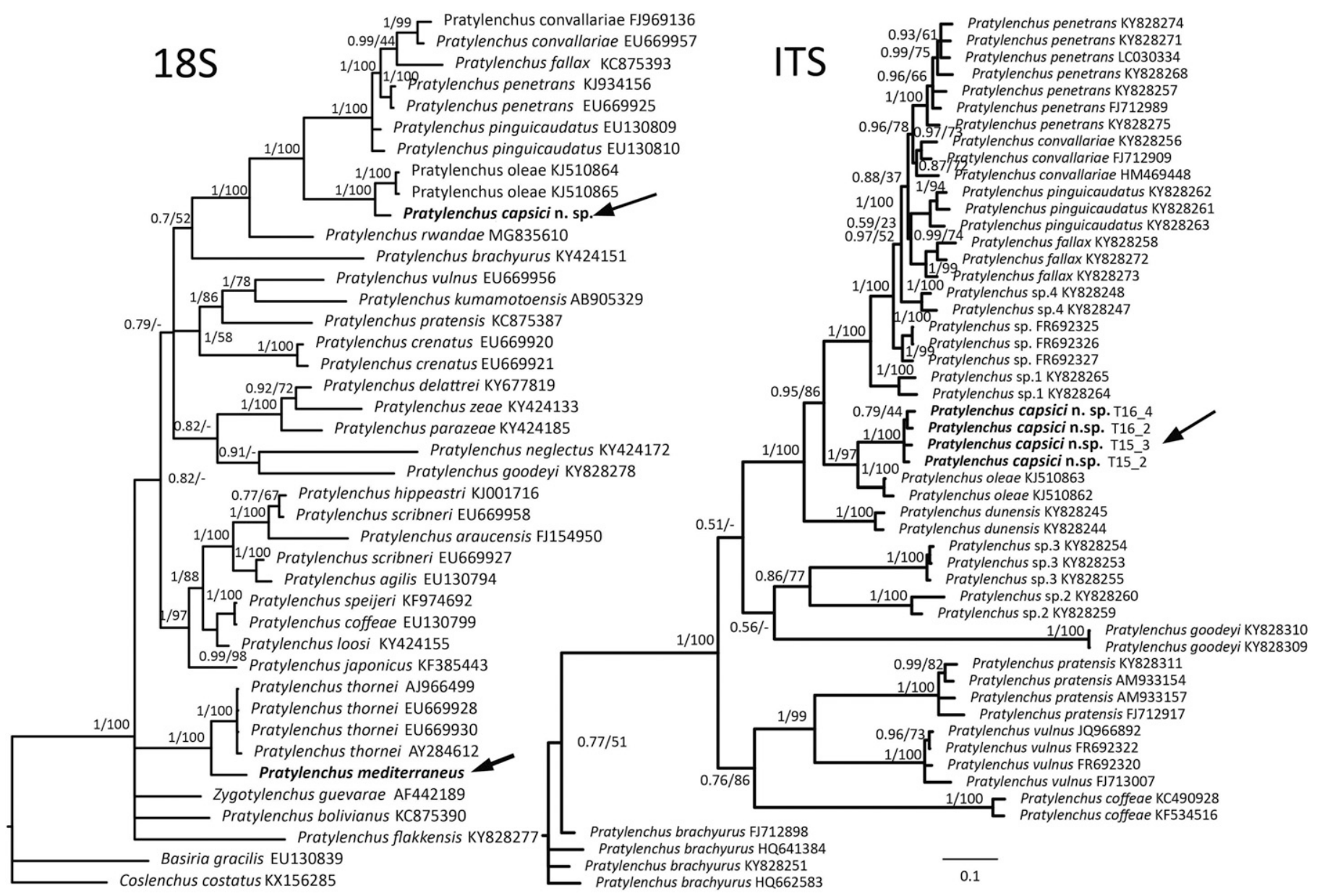

$\overline{0.03}$

Fig. 5. Bayesian 50\% majority-rule consensus tree inferred on $18 \mathrm{~S}$ ribosomal RNA (18S, left) and internal transcribed spacer (ITS, right) aligned with G-INS-i implemented in MAFFT. Section's order of support values: posterior probability/bootstrap. New species are indicated by arrows and new sequences original to this study are indicated in bold. 
final tree was produced after removing 2,000 samples (20\%) as burn-ins, and the maximum clade credibility tree was calculated using TreeAnnotator 1.8 (Drummond et al. 2012). For the bPTP method, an unrooted Bayesian 50\% majority-rule consensus tree was used containing only ingroups and unique haplotypes; $1 \times 10^{6}$ Markov chain Monte Carlo (MCMC) generations were performed using an online server (https://species.h-its.org/). For the ABGD method, the alignment without outgroups and only unique haplotypes was used. ABGD analyses were performed using the online version of the program (http://wwwabi.snv.jussieu.fr/ public/abgd/abgdweb.html) with the default program settings, and distances were calculated using the Jukes-Cantor (JC69) substitution model.

Population structure. To study the relationships between populations and their geographical distributions, we estimated COI haplotype diversity and population genetic structure using the PopART program (Leigh and Bryant 2015) by means of the TCS networks (Clement et al. 2002).

We applied the Bayesian clustering program STRUCTURE v2.3.4 (Falush et al. 2003, 2007; Pritchard et al. 2000) to further estimate population structure, possible migrants, and individuals with admixed population ancestry. In the absence of prior knowledge of relationships, and given the capacity for dispersal across geographical barriers by agricultural practice, we used the 'admixture' model for analyses. We used the a priori constraint of number of populations, from a single, panmictic population throughout the entire Arava rift $(K=1)$ to a series of populations including all sampling sites $(\mathrm{K}=8)$. We ran five independent analyses, each for 5 million MCMC iterations, discarding 500,000 burn-ins. We selected the preferred number of populations (K value) based on the
$\Delta \mathrm{K}$ method (Evanno et al. 2005) and maximum posterior probability method (Pritchard et al. 2000) using the program CLUMPAK (Kopelman et al. 2015).

\section{RESULTS}

Description of Pratylenchus capsici n. sp. The measurements are listed in Table 1. Female. Body slender, vermiform, straight or slightly curved ventrally. The lip region is slightly offset from the body contour, with three annuli distinctly higher than the adjoining body annuli. In a single specimen, four distinct annuli on one side of the lip region and three on the other side were observed (Fig. 1D). En face view characterized by a divided face with rectangular subdorsal and subventral lips fused to an oral disc in a dumbbell pattern which is separated from the lateral lip sectors by two almost straight incisures forming an obtuse angle (Figs. 1A and B and $2 \mathrm{~J})$, in accordance with group 2 in the classification scheme of Corbett and Clark (1983). Lateral fields with four equidistant completely areolated lines, occupying almost one-third of the body width at midbody (Figs. 1L to N, 2I, and 3Q). Stylet well developed, conus half of entire length, basal knobs strongly developed and rounded to slightly anteriorly concave. Pharyngeal procorpus narrowing just anterior to rounded-oval, muscular median bulb. Valve of median bulb conspicuous. Secretory-excretory pore at the level of or slightly posterior to the pharyngo-intestinal junction. Hemizonid located immediately anterior to the secretory-excretory pore to approximately 3 annuli anterior. Pharyngeal glands overlapping intestine ventrally. Reproductive system monoprodelphic, oocytes arranged in a single row. Spermatheca large, round to slightly oval, full of sperm, 11 to $18 \mu \mathrm{m}$ in length (Figs. $2 \mathrm{E}$ and $\mathrm{F}$ and $3 \mathrm{H}$ and $\mathrm{I}$ ). Vulva protruding, lips

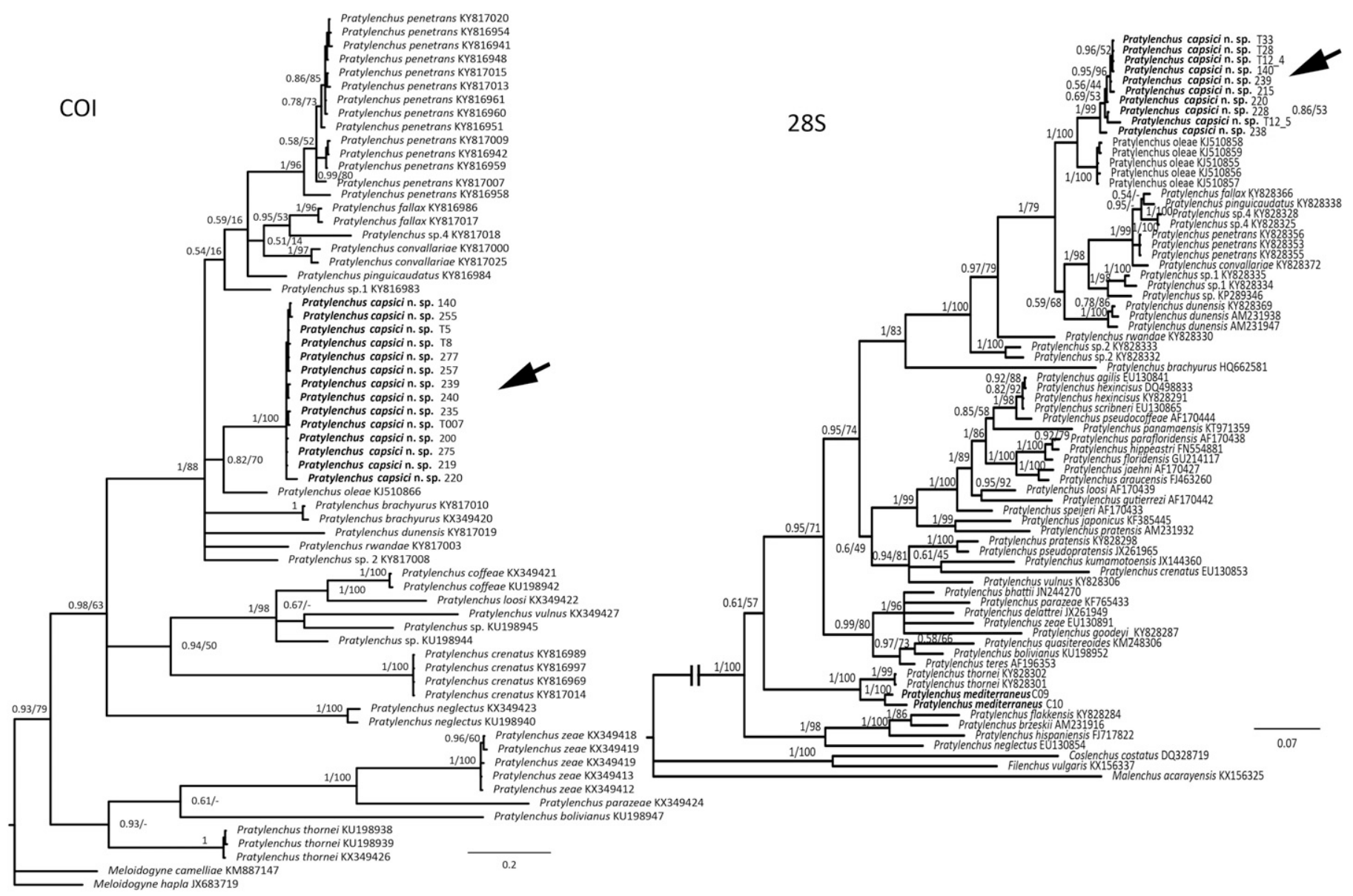

Fig. 6. Bayesian 50\% majority-rule consensus tree inferred on cytochrome c oxidase subunit 1 (COI, left) and D2/D3 of 28S ribosomal RNA (28S, right) aligned with G-INS-i implemented in MAFFT. Section's order of support values: posterior probability/bootstrap. New species are indicated by arrows and new sequences original to this study are indicated in bold. 
well developed, no lateral flaps or epiptygma. Postuterine sac (PUS) well developed, 1.1 to 1.7 times the vulval body diameter in length. Tail terminus smooth, conoid-rounded to subcylindrical. Phasmid at or slightly posterior to midtail level.
Male. Similar to female except in reproductive system, and with a slightly smaller body length. Testis outstretched, short. Spicules paired, weakly cephalated, ventrally arcuate. Gubernaculum slightly curved. Tail conical, elongate, characteristically bent on ventral side,

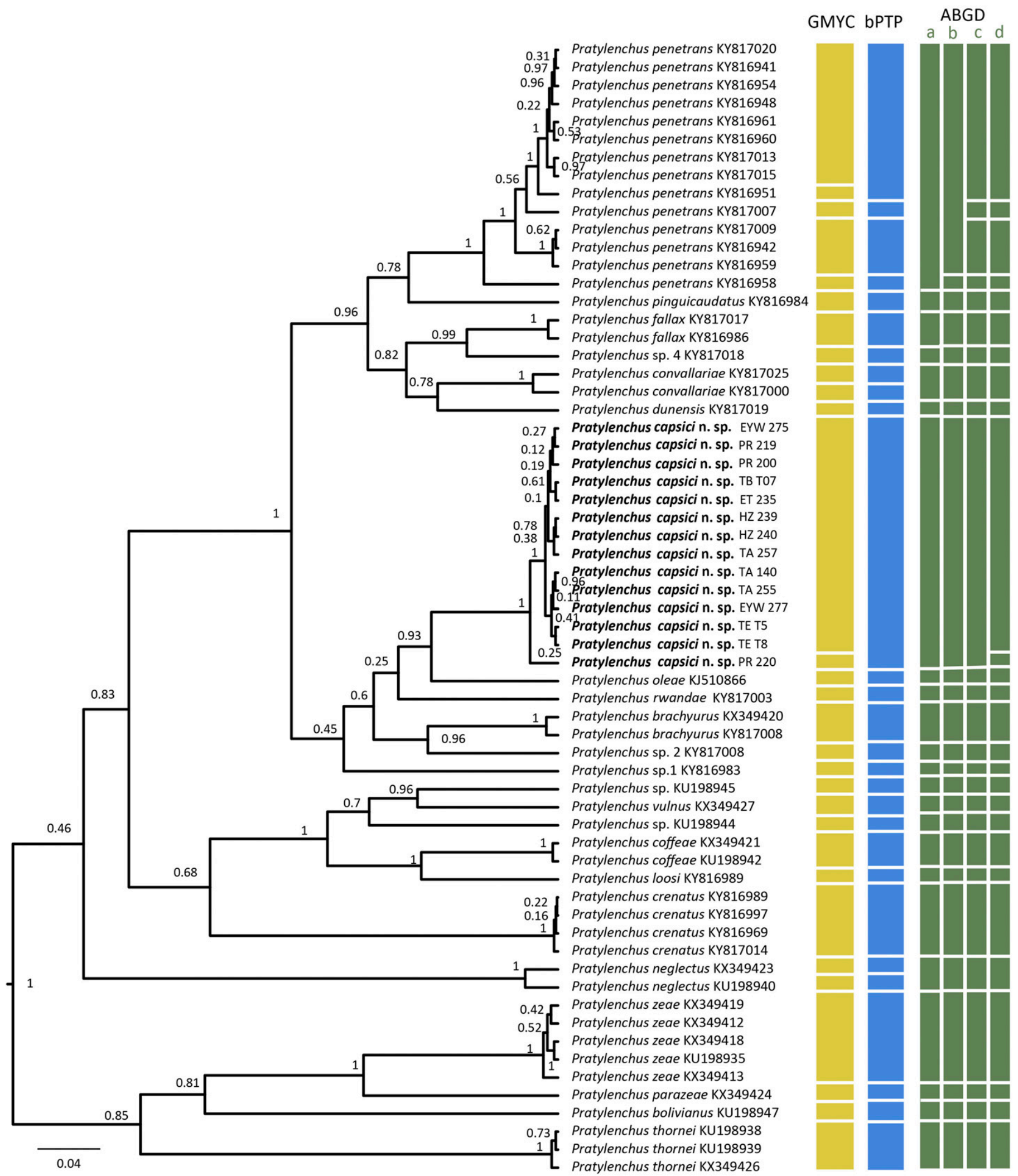

Fig. 7. Molecular species-delimitation analysis of the Pratylenchus spp. by three methods: generalized mixed yule coalescent model (GMYC), a Bayesian implementation of the Poisson tree processes (bPTP), and automatic barcode gap discovery (ABGD). Delimitation results are visualized as bars on an ultrametric Bayesian maximum clade credibility tree of the cytochrome c oxidase subunit 1 gene. For the ABGD analysis, columns a to d correspond to the 23, 24, 26, and 27 species grouping, respectively, as recovered for different prior intraspecific divergence assumptions. Bayesian posterior probabilities are indicated on the branches of the phylogenetic tree. New sequences original to this study are indicated in bold. 
enveloped by a poorly protruding, crenate bursa (Figs. $1 \mathrm{~J}$ and K, 2D, and $3 \mathrm{C}$ and D).

Type host and symptoms. P. capsici n. sp. was found in roots of sweet pepper (Capsicum annuum) at the nethouse in Tsofar, Arava rift, Israel (GPS coordinates $30^{\circ} 33^{\prime} 11.6^{\prime \prime} \mathrm{N}, 35^{\circ} 11^{\prime} 30.3^{\prime \prime} \mathrm{E}$ ). Two additional populations were found from Chenopodium album and $S$. oleraceus in the nethouse at Ein Yahav but at much lower density. The infected sweet pepper had necrotic lesions on the surface and throughout the cortex of the infected root (Fig. 4). Aboveground parts of plant showed stunted growth, yellowing, and marginal and tip curving of the leaves.

Type material. Holotype female, two female and three juvenile paratypes are deposited on one slide at the Ghent University Museum, Zoology Collections, collection number UGMD104364. Additional paratypes are deposited in the Nematology Research Unit of the Volcani Center, Israel. The new species name has been registered at ZooBank (identifier: F0EA56A6-BEDA-4378-893DBAEFE980E9AA).

Etymology. The species epithet is derived from the name of its host, Capsicum annuum.

Diagnosis and relationships. P. capsici $\mathrm{n}$. sp. is characterized by a combination of the following traits: relatively long body (559 to $642 \mu \mathrm{m}$ ), lip region slightly offset from body contour, bearing three annuli. A divided SEM face, with rectangular subdorsal and subventral lips fused with oral disc in a dumbbell pattern which is separated from lateral lip sectors by two incisures forming an obtuse angle (group 2 according to Corbett and Clark [1983]); a stylet 14 to $15 \mu \mathrm{m}$ long; lateral fields with four areolated incisures, a functional spermatheca, and numerous males.

Morphologically, P. capsici $\mathrm{n}$. sp. can be distinguished from all other known species by a number of specific characteristics resulting from its specific matrix code Castillo and Vovlas (2007): A2, B2, C2, D2, E2, F5(4), G3(2), H2, I1(2), J1, and K2 (variation in characteristics is given in parentheses). For a detailed comparison of morphologically and molecularly related species, see Table 2. $P$. capsici $\mathrm{n}$. sp. is most similar to $P$. oleae (with 10 identical traits out of 11 , according to the matrix code) but differs in the presence of males (versus their absence), a functional spermatheca (versus nonfunctional and empty), a larger body (559 to 642 versus 412 to $511 \mu \mathrm{m}$ ), and a shorter stylet (14 to 15 versus 15 to $17 \mu \mathrm{m})$. With P. bhattii, P. pseudofallax, and P. unzenensis, $P$. capsici n. sp. shares the combination of three lip annuli, a round functional spermatheca, common presence of males, and a stylet of 13 to $16 \mu \mathrm{m}$. It differs from $P$. bhattii in having an areolated (versus smooth) lateral region, striated (versus smooth) female tail tip, and a longer PUS (22 to 38 versus 11 to $22 \mu \mathrm{m})$. It differs from P. pseudofallax in its areolated (versus smooth) lateral region, larger body (559 to 642 versus 415 to $525 \mu \mathrm{m}$ ), and most of its morphometric ratios. It differs from $P$. unzenensis in its round (versus oval) spermatheca, striated (versus smooth) female tail tip, and larger body (559 to 642 versus 368 to $470 \mu \mathrm{m}$ ).

Phylogenetic relationships. The amplification of $28 \mathrm{~S}$, ITS, $18 \mathrm{~S}$, and COI regions yielded fragments of approximately 748,778 ,
1,797, and $441 \mathrm{bp}$, respectively. The pairwise comparison of the sequence of $P$. capsici n. sp. with other Pratylenchus sequences from GenBank gave the highest similarity to $P$. oleae for all genes (nucleotide differences: $18 \mathrm{~S}, 22$ to $23 \mathrm{bp}, 1.19$ to $1.24 \%$; $28 \mathrm{~S}, 33$ to $45 \mathrm{bp}, 3.83$ to $5.23 \%$; ITS, 59 to $148 \mathrm{bp}, 4.25$ to $10.67 \%$; and COI, 59 to $62 \mathrm{bp}, 13.1$ to $13.78 \%$ ).

Phylogenetic relationships among Pratylenchus spp. inferred from $18 \mathrm{~S}, 28 \mathrm{~S}$, ITS, and COI sequences were congruent across analyses and, in general, our results supported those of previous analyses (Janssen et al. 2017; Palomares-Rius et al. 2014; Subbotin et al. 2008). In all analyses, $P$. capsici $\mathrm{n}$. sp. was well supported as a sister group of $P$. oleae $(18 \mathrm{~S}$ : posterior probability $[\mathrm{PP}]=1, \mathrm{BS}=100 ; 28 \mathrm{~S}$ : $\mathrm{PP}=1, \mathrm{BS}=100$; ITS: $\mathrm{PP}=1, \mathrm{BS}=97$; and COI: $\mathrm{PP}=0.82, \mathrm{BS}=70$ ) (Figs. 5 and 6). In the $28 \mathrm{~S}$ phylogeny, $P$. capsici $\mathrm{n}$. sp. is nested in the monophyletic Penetrans group (Janssen et al. 2017), including $P$. rwandae, $P$. convallariae, $P$. dunensis, $P$. fallax, $P$. oleae, $P$. penetrans, $P$. pinguicaudatus, and three undescribed species (Pratylenchus sp. 1, 2, and 4), or clade IV (Palomares-Rius et al. 2014), including the aforementioned species plus $P$. brachyurus. Similar placements were also seen in 18S and ITS (except for a divergent placement of $P$. brachyurus) but the interspecific relationship was not resolved for COI. In addition, the newly obtained $18 \mathrm{~S}$ and $28 \mathrm{~S}$ sequences from $P$. mediterraneus were fully supported $(\mathrm{PP}=1$, $\mathrm{BS}=100$ ) as sister to $P$. thornei, concurring with De Luca et al. (2004).

Molecular species delimitation. In an attempt to compare P. capsici $\mathrm{n}$. sp. with other similar species and identify populations that may merit species rank, we employed species delimitation using GMYC, bPTP, and ABGD methods based on COI sequences (Fig. 7). We included all recovered haplotypes of the new species, as well as of other Pratylenchus spp. that are available in GenBank, and the resultant alignment contained 63 different 444-bp-long haplotypes. Molecular species delimitation appointed the highest species number using the single-threshold GMYC model prediction $(n=30)$, followed by 28 species according to bPTP, while ABGD revealed variation in the number of species-from 23 to 27 - according to the models and priors used. In general, the applied methods were largely congruent among themselves and with traditional methods, and the $P$. capsici $\mathrm{n}$. sp. populations were well separated from all known species. Surprisingly, in two cases (GMYC and 27 species of ABGD), one haplotype (at the PR site) was separated from the other populations and, thus, according to these species-delimitation methods, can be separated into two cryptic species which are morphologically and morphometrically identical. This variable number of estimated species is not unexpected given that molecular species-delimitation analyses are known to generate a variety of different species hypotheses (Kekkonen and Hebert 2014; Prévot et al. 2013). We opted to follow the most stringent criterion, by which a species is only recognized when it is supported by morphological and molecular species delimitation. Consequently, the population from PR is considered to represent intraspecific variation.

Population structure. In total, $68 \mathrm{COI}$ sequences obtained from nine samples were used for the population analysis. The most

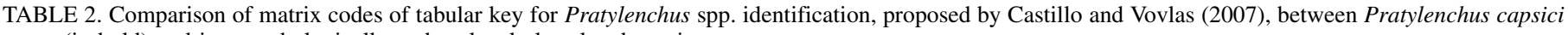
n. sp. (in bold) and its morphologically and molecularly related species

\begin{tabular}{|c|c|c|c|c|c|c|c|c|c|c|c|}
\hline Species & A & B & $\mathrm{C}$ & $\mathrm{D}$ & $\mathrm{E}$ & $\mathrm{F}$ & $\mathrm{G}$ & $\mathrm{H}$ & $\mathrm{I}$ & $\mathrm{J}$ & K \\
\hline P. capsici n. sp. & 2 & 2 & 2 & 2 & $2,1,3$ & 5,4 & 3,2 & 2 & 1,2 & 1 & 2 \\
\hline P. brachyurus & 1 & 2 & 4 & 1 & 4 & 3 & 3 & 1 & 4 & 2,3 & 1 \\
\hline P. convallariae & 2 & 2 & 3 & 2 & 2 & 6 & 2 & 2 & 3 & 1 & 1 \\
\hline P. crenatus & 2 & 2 & 3 & 1 & 3 & 3 & 2 & 2 & 1 & 3 & 1 \\
\hline P. dunensis & 1 & 2 & 3 & 2 & 2 & 4 & 1 & 1 & 4 & 1 & 2 \\
\hline P. fallax & 2 & 2 & 3 & 2 & 2 & 3 & 3 & 2 & 2 & 1 & 1 \\
\hline P. mediterraneus & 2 & 2 & 2 & 2 & 2 & 3 & 2 & 1 & 3 & 1 & 1 \\
\hline P. oleae & 2 & 1 & 2,3 & 2 & 2,3 & $3,4,5$ & 2,3 & 2 & 1,2 & 1 & 2 \\
\hline P. penetrans & 2 & 2 & 3 & 2 & 3 & 4 & 2 & 1 & 3 & 1 & 1 \\
\hline P. pinguicaudatus & 2 & 1 & 3 & 1 & 3 & 1 & 2 & 1 & 4 & 1 & 2 \\
\hline P. rwandae & 2 & 1 & 2 & 2,3 & 2 & 3,4 & 2,3 & 1 & 1,2 & 3 & 1 \\
\hline
\end{tabular}


interesting general result was the presence of multiple haplotypes occurring in a relatively small geographical region (approximately $90 \mathrm{~km}$ ). In total, 14 unique COI haplotypes were identified (Fig. 8A and B). Haplotype diversity was highest in TA (five haplotypes), followed by EYW (three haplotypes), and TE (three haplotypes), whereas only one haplotype was found in EYP and TB. Most haplotypes were closely related and separated by a single mutation, while the most common haplotype in PR (H14) was the exception, diverging by 10 mutational steps. Most of the sampling sites were characterized by their own endemic haplotype (12 haplotypes were only present once), no ubiquitous haplotype could be found, and only three sampling locations shared 2 haplotypes (EYW, TA, and TE shared haplotype H5 and ET, TE, and TA shared haplotype H12). Haplotype H2 was found in two adjacent sites (EYP for pepper and EYW for weeds). Interestingly, it was the only haplotype in EYP but one of three in EYW, suggesting possible dispersal from weeds to pepper. Conversely, H10 was the only haplotype found in TB but it was not present in the adjacent TA or in any other sites,
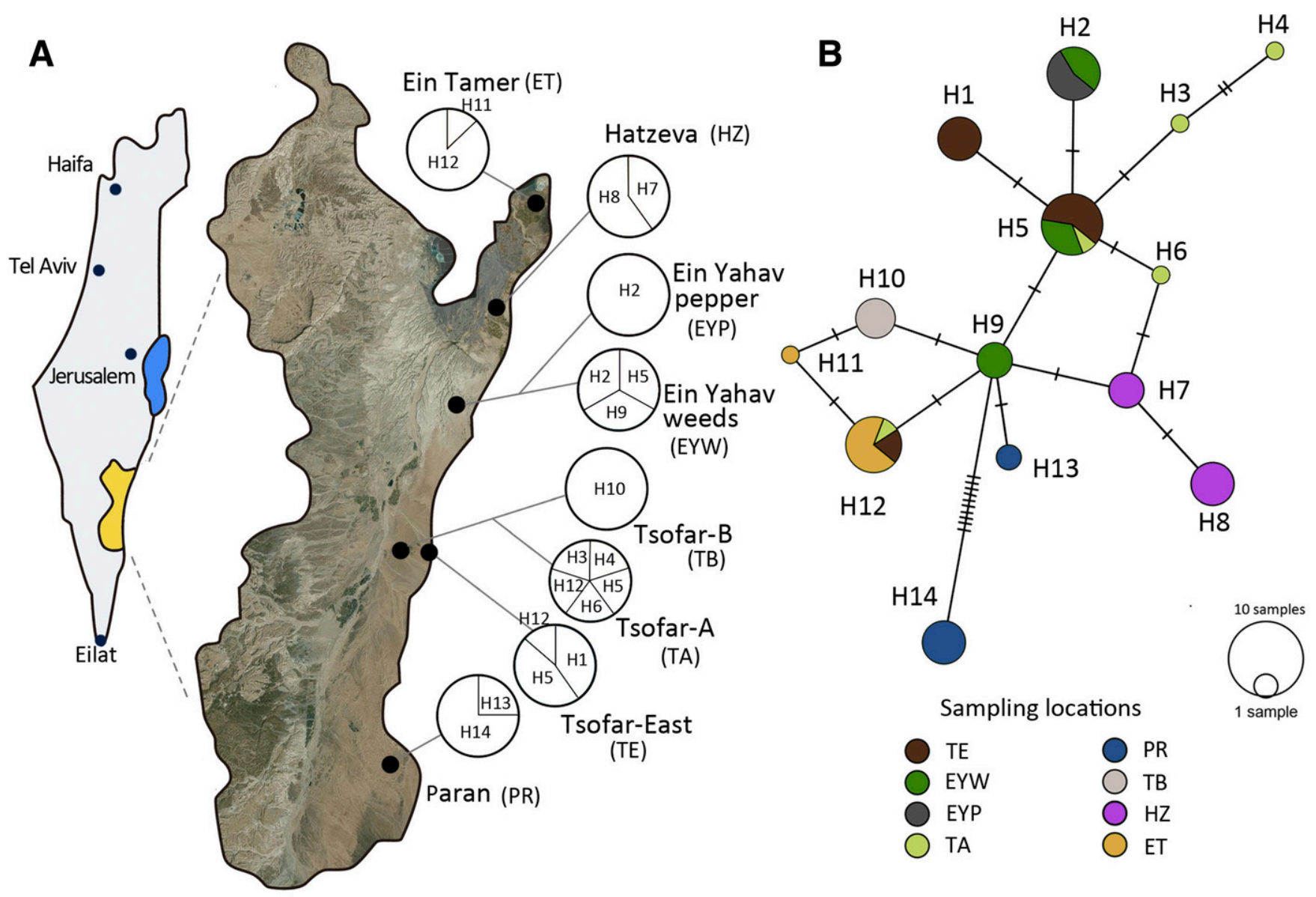

C

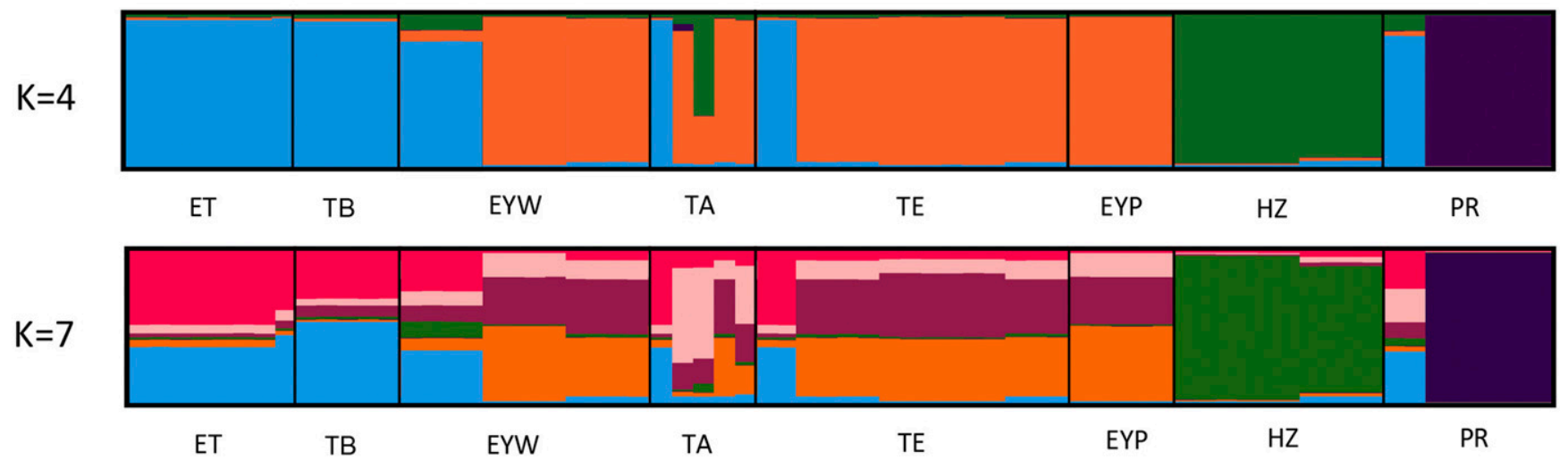

Fig. 8. Geographical distribution of the sampling sites, cytochrome c oxidase subunit 1 haplotype network, and the inferred population structure of Pratylenchus capsici n. sp. in Arava rift, Israel. A, Geographic location of Arava rift region and the distribution of sampling sites. Pie chart indicates the composition and proportion of haplotypes in each location. B, TCS haplotype network inferred from PopARTC. Each circle corresponds to one haplotype and its size is proportional to its frequency. Each line connecting the haplotypes refers to a mutational step. Marks on the lines indicate the number of steps. Shades correspond to different sampling locations and names are given in abbreviations. C, Population structure inferred from STRUCTURE runs with the best probability values measured by $\Delta K(K=4)$ and maximum posterior probability method $(K=7)$. Sampling regions are separated by black lines. Clusters with similar shades are more closely related. Within each cluster, an individual sequenced nematode corresponds to a vertical segment that reflects its ancestry. Mixed ancestries are indicated by differently shaded sectors, corresponding to inferred genetic percentages of the corresponding clusters. 
suggesting that this population may have been recently introduced from an unknown source.

According to the maximum posterior probability method (Pritchard et al. 2000), the most likely number of clusters $(\mathrm{K})$ is 7 , whereas the $\Delta K$ method (Evanno et al. 2005) suggested $K=4(\Delta K=$ 60.6). However, the $\Delta K$ values for $K=7$ show a pronounced second peak $(\Delta \mathrm{K}=25.8)$, giving at least some support to the maximum posterior probability approach. Based on this evidence, the inferred population structure for both $\mathrm{K}=4$ and $\mathrm{K}=7$ is presented (Fig. $8 \mathrm{C}$ ). Under both $\mathrm{K}$ values, the recognized clusters did not correspond to their geographical distributions. For example, ET is geographically adjacent to $\mathrm{HZ}$ but lumped together with TB (Fig. 8A and C). Regarding each sampling site, more ancestry admixture appeared when $\mathrm{K}=7$ compared with $\mathrm{K}=4$, except for $\mathrm{HZ}$ and $\mathrm{PR}$, where only very minor admixtures were detected. Taken together, the network and population structure analyses suggest the existence of historical admixture across the range; however, all sampling sites are currently well separated by unique haplotype compositions.

\section{DISCUSSION}

Nematodes of the genus Pratylenchus is notorious for being difficult to identify at the species level. Despite a few well-defined diagnostic characteristics (e.g., presence or absence of males and nature of the lateral field), most widely used characteristics are continuous and overlapping (e.g., stylet size and PUS length) or subject to interpretation (e.g., shape of spermatheca and tail) (Castillo and Vovlas 2007; Roman and Hirschmann 1969; Tarte and Mai 1976). Several biochemical and molecular methods have been used for accurate diagnosis, including isozyme electrophoresis (Andrés et al. 2000; Ibrahim et al. 1995), restriction fragment analysis of ITS (Waeyenberge et al. 2000), species-specific primers (Al-Banna et al. 2004; Palomares-Rius et al. 2014; Subbotin et al. 2008; Troccoli et al. 2016), duplex and quantitative PCR methods (De Luca et al. 2012; Waeyenberge et al. 2009), and ribosomal and mitochondrial gene-based barcoding and species delimitation (De Luca et al. 2011; Janssen et al. 2017; Subbotin et al. 2008). Today, sequence-based molecular barcodes are most often used; however, they are also often intraspecifically variable (Janssen et al. 2017). In this study, we described $P$. capsici n. sp. using integrative approaches and the results support recognition of $P$. capsici $\mathrm{n}$. sp. as a new species. The inclusion of phylogeography and population genetics analysis underscores the great potential of such methods as tools in plant-parasitic nematology to understand the nematodes' life history and transmission. In most cases, novel and distinct molecular lineages may be recognized by morphological data. However, in this case, two cryptic species within P. capsici n. sp. were appointed by some molecular species-delimitation methods, whereas no morphological differences (Tables 1 and 2) were observed. Given that single-locus data represent the history of a single gene that might not be representative of the organism's history (Fujita et al. 2012), we consider traditional morphology-based taxonomy to be a reasonable and, in fact, indispensable basis for species hypotheses. Therefore, we followed the consensus protocol proposed by Padial et al. (2010), whereby the molecularly delimited lineages are not recognized as new species unless they are morphologically diagnosable and supported by independent posthoc analysis.

In the present study, sampling throughout the Arava rift range allowed for robust genetic analyses of the populations. The results of the mitochondrial haplotype network analyses revealed high COI haplotype diversity in P. capsici n. sp. (14 unique haplotypes). Such high diversity within this limited geographical region is surprising because, for example, only 16 haplotypes were provided from five countries with highly variable $P$. penetrans populations (Janssen et al. 2017), and $P$. mediterraneus samples from four locations in Israel shared a single haplotype (unpublished data). While not providing support for a straightforward genetic-geographical pattern, our STRUCTURE analyses did reveal admixtures among the sampling sites (except for HZ, with a less admixed composition), suggesting either retention of ancestral polymorphisms or contemporary gene flow. However, the latter is unlikely to be the main reason because (i) most of the haplotypes were only present in a specific location (12 of 14 haplotypes), and those locations sharing haplotypes were not necessarily geographically proximate (EYW, TA, and TE for haplotype H5 and ET, TE, and TA for haplotype $\mathrm{H} 12)$; (ii) the hyperaridity and hypersalinity in this area are extremely unfavorable, posing a strong habitat barrier, and the nematodes are entirely absent in the open area below sea level (PenMouratov et al. 2010); and (iii) man-mediated dispersal is limited because the spread of pathogens is well controlled in highly developed and commercialized sampling regions. Conversely, on a small scale (e.g., within one nethouse), contemporary gene flow is likely to contribute to the observed genetic patterns. EYW were collected from weed (Chenopodium album, a widespread species in the nethouse of Arava rift) roots, a few meters away from sweet pepper root (EYP). The geographical proximity gives rise to the possibility of population migration or man-mediated transport. Indeed, EYW has three haplotypes (H2, H5, and H9) whereas EYP bears only one of them (H2), suggesting plausible dispersal from EYW to EYP. Interestingly, the sister species $P$. oleae was also recovered in both wild and cultivated olive (Palomares-Rius et al. 2014), and an unidentified Pratylenchus population was recovered from a natural environment in a closely related area (Shukurov et al. 2005). Several Pratylenchus spp. (e.g., P. brachyurus, P. coffeae, and $P$. vulnus) have a wide range of host plants (Castillo and Vovlas 2007), and the ability to parasitize a wide range of weed species is also known for $P$. penetrans (Bélair et al. 2007). This suggests that $P$. capsici n. sp. may be native and parasitize wild plants, or that it was introduced by another, unknown, source but coincidently survived in the weeds. Taken together, our results indicate that weeds are important either as the original nematode source or in maintaining the population. Further analyses with geographically broader sampling and more plant species are needed to clarify this.

\section{ACKNOWLEDGMENTS}

We thank M. Couvreur for the SEM analysis.

\section{LITERATURE CITED}

Abascal, F., Zardoya, R., and Telford, M. J. 2010. TranslatorX: Multiple alignment of nucleotide sequences guided by amino acid translations. Nucleic Acids Res. 38:W7-W13.

Al-Banna, L., Ploeg, A. T., Williamson, V. M., and Kaloshian, I. 2004. Discrimination of six Pratylenchus species using PCR and species-specific primers. J. Nematol. 36:142-146.

Andrés, M. F., Pinochet, J., Hernández-Dorrego, A., and Delibes, A. 2000. Detection and analysis of inter-and intraspecific diversity of Pratylenchus spp. using isozyme markers. Plant Pathol. 49:640-649.

Bélair, G., Dauphinais, N., Benoit, D. L., and Fournier, Y. 2007. Reproduction of Pratylenchus penetrans on 24 common weeds in potato fields in Quebec. J. Nematol. 39:321.

Blaxter, M. L., De Ley, P., Garey, J. R., Liu, L. X., Scheldeman, P., Vierstraete, A., Vanfleteren, J. R., Mackey, L. Y., Dorris, M., and Frisse, L. M. 1998. A molecular evolutionary framework for the phylum Nematoda. Nature 392:71-75.

Bowles, J., Blair, D., and McManus, D. P. 1992. Genetic variants within the genus Echinococcus identified by mitochondrial DNA sequencing. Mol. Biochem. Parasitol. 54:165-173.

Bybd, D. W., Jr., Kirkpatrick, T., and Barker, K. R. 1983. An improved technique for clearing and staining plant tissues for detection of nematodes. J. Nematol. 15:142-143.

Castillo, P., and Vovlas, N. 2007. Pratylenchus (Nematoda: Pratylenchidae): Diagnosis, Biology, Pathogenicity and Management. Brill, Leiden, The Netherlands.

Clement, M., Snell, Q., Walker, P., Posada, D., and Crandall, K. 2002. TCS: Estimating gene genealogies. Page 184 in: Proc. 16th Int. Parallel Distributed Processing Symp. IEEE.

Corbett, D., and Clark, A. 1983. Surface features in the taxonomy of Pratylenchus species. Rev. Nematol. 6:85-98. 
Darriba, D., Taboada, G. L., Doallo, R., and Posada, D. 2012. jModelTest 2: More models, new heuristics and parallel computing. Nat. Methods 9:772.

De Luca, F., Fanelli, E., Di Vito, M., Reyes, A., and De Giorgi, C. 2004. Comparison of the sequences of the D3 expansion of the $26 \mathrm{~S}$ ribosomal genes reveals different degrees of heterogeneity in different populations and species of Pratylenchus from the Mediterranean region. Eur. J. Plant Pathol. 110:949-957.

De Luca, F., Reyes, A., Troccoli, A., and Castillo, P. 2011. Molecular variability and phylogenetic relationships among different species and populations of Pratylenchus (Nematoda: Pratylenchidae) as inferred from the analysis of the ITS rDNA. Eur. J. Plant Pathol. 130:415-426.

De Luca, F., Troccoli, A., Duncan, L. W., Subbotin, S. A., Waeyenberge, L., Coyne, D. L., Brentu, F. C., and Inserra, R. N. 2012. Pratylenchus speijeri n. sp.(Nematoda: Pratylenchidae), a new root-lesion nematode pest of plantain in West Africa. Nematology 14:987-1004.

Drummond, A. J., Suchard, M. A., Xie, D., and Rambaut, A. 2012. Bayesian phylogenetics with BEAUti and the BEAST 1.7. Mol. Biol. Evol. 29: 1969-1973.

Evanno, G., Regnaut, S., and Goudet, J. 2005. Detecting the number of clusters of individuals using the software STRUCTURE: A simulation study. Mol. Ecol. 14:2611-2620

Ezard, T., Fujisawa, T., and Barraclough, T. G. 2009. Splits: SPecies' LImits by Threshold Statistics. Online publication. R package, version 1.0-19/r52. https://rdrr.io/rforge/splits/

Falush, D., Stephens, M., and Pritchard, J. K. 2003. Inference of population structure using multilocus genotype data: Linked loci and correlated allele frequencies. Genetics 164:1567-1587.

Falush, D., Stephens, M., and Pritchard, J. K. 2007. Inference of population structure using multilocus genotype data: Dominant markers and null alleles. Mol. Ecol. Notes 7:574-578.

Fujita, M. K., Leaché, A. D., Burbrink, F. T., McGuire, J. A., and Moritz, C. 2012. Coalescent-based species delimitation in an integrative taxonomy. Trends Ecol. Evol. 27:480-488.

Geraert, E. 2013. The Pratylenchidae of the World: Identification of the Family Pratylenchidae (Nematoda: Tylenchida). Academia Press, Gent, Belgium.

Hodda, M., Collins, S. J., Vanstone, V. A., Hartley, D., Wanjura, W., and Kehoe, M. 2014. Pratylenchus quasitereoides n. sp. from cereals in Western Australia. Zootaxa 3866:277-288.

Ibrahim, S. K., Perry, R. N., and Webb, R. M. 1995. Use of isoenzyme and protein phenotypes to discriminate between six Pratylenchus species from Great Britain. Ann. Appl. Biol. 126:317-327.

Janssen, T., Karssen, G., Orlando, V., Subbotin, S. A., and Bert, W. 2017. Molecular characterization and species delimiting of plant-parasitic nematodes of the genus Pratylenchus from the penetrans group (Nematoda: Pratylenchidae). Mol. Phylogenet. Evol. 117:30-48.

Jones, M. G. K., and Fosu-Nyarko, J. 2014. Molecular biology of root lesion nematodes (Pratylenchus spp.) and their interaction with host plants. Ann. Appl. Biol. 164:163-181.

Katoh, K., and Standley, D. M. 2013. MAFFT multiple sequence alignment software version 7: Improvements in performance and usability. Mol. Biol. Evol. 30:772-780.

Kekkonen, M., and Hebert, P. D. N. 2014. DNA barcode-based delineation of putative species: Efficient start for taxonomic workflows. Mol. Ecol. Resour. 14:706-715

Kopelman, N. M., Mayzel, J., Jakobsson, M., Rosenberg, N. A., and Mayrose, I. 2015. Clumpak: A program for identifying clustering modes and packaging population structure inferences across K. Mol. Ecol. Resour. 15: 1179-1191.

Leigh, J. W., and Bryant, D. 2015. popart: Full-feature software for haplotype network construction. Methods Ecol. Evol. 6:1110-1116.

Miller, M., Pfeiffer, W., and Schwartz, T. 2010. Creating the CIPRES Science Gateway for inference of large phylogenetic trees. Pages 1-8 in: Gateway Computing Environ. Workshop (GCE) IEEE, New Orleans. in:

Nadler, S., Felix, M.-A., Frisse, L., Sternberg, P. W., De Ley, P., and Thomas, W. K. 1999. Molecular and morphological characterisation of two reproductively isolated species with mirror-image anatomy (Nematoda: Cephalobidae). Nematology 1:591-612.

Nicol, J. M., Turner, S. J., Coyne, D. L., Den Nijs, L., Hockland, S., and Maafi, Z. T. 2011. Current nematode threats to world agriculture. Pages 21-43 in: Genomics and Molecular Genetics of Plant-Nematode Interactions. J. Jones, G. Gheysen, and C. Fenoll, eds. Springer, Dordrecht, The Netherlands.
Padial, J. M., Miralles, A., De la Riva, I., and Vences, M. 2010. The integrative future of taxonomy. Front. Zool. 7:16.

Palomares-Rius, J. E., Guesmi, I., Horrigue-Raouani, N., Cantalapiedra-Navarrete, C., Liébanas, G., and Castillo, P. 2014. Morphological and molecular characterisation of Pratylenchus oleae n. sp.(Nematoda: Pratylenchidae) parasitizing wild and cultivated olives in Spain and Tunisia. Eur. J. Plant Pathol. 140:53-67.

Pen-Mouratov, S., Myblat, T., Shamir, I., Barness, G., and Steinberger, Y. 2010. Soil biota in the Arava Valley of Negev Desert, Israel. Pedosphere 20: 273-284.

Pons, J., Barraclough, T. G., Gomez-Zurita, J., Cardoso, A., Duran, D. P., Hazell, S., Kamoun, S., Sumlin, W. D., and Vogler, A. P. 2006. Sequencebased species delimitation for the DNA taxonomy of undescribed insects. Syst. Biol. 55:595-609.

Prévot, V., Jordaens, K., Sonet, G., and Backeljau, T. 2013. Exploring species level taxonomy and species delimitation methods in the facultatively selffertilizing land snail genus Rumina (Gastropoda: Pulmonata). PLoS One 8: e60736.

Pritchard, J. K., Stephens, M., and Donnelly, P. 2000. Inference of population structure using multilocus genotype data. Genetics 155:945-959.

Puillandre, N., Lambert, A., Brouillet, S., and Achaz, G. 2012. ABGD, Automatic Barcode Gap Discovery for primary species delimitation. Mol. Ecol. 21:1864-1877.

Rambaut, A., Drummond, A. J., Xie, D., Baele, G., and Suchard, M. A. 2018. Posterior summarization in Bayesian phylogenetics using Tracer 1.7. Syst. Biol. 67:901-904

Roman, J., and Hirschmann, H. 1969. Morphology and morphometrics of six species of Pratylenchus. J. Nematol. 1:363-386.

Ronquist, F., Teslenko, M., Van Der Mark, P., Ayres, D. L., Darling, A., Höhna, S., Larget, B., Liu, L., Suchard, M. A., and Huelsenbeck, J. P. 2012. MrBayes 3.2: Efficient Bayesian phylogenetic inference and model choice across a large model space. Syst. Biol. 61:539-542.

Shukurov, N., Pen-Mouratov, S., Genzer, N., Plakht, J., and Steinberger, Y. 2005. Distribution of soil microbial biomass and free-living nematode population in terrace chronosequences of Makhtesh-Ramon crater. Arid Land Res. Manage. 19:197-213.

Singh, P. R., Nyiragatare, A., Janssen, T., Couvreur, M., Decraemer, W., and Bert, W. 2018. Morphological and molecular characterisation of Pratylenchus rwandae n. sp.(Tylenchida: Pratylenchidae) associated with maize in Rwanda. Nematology 20:781-794.

Sohlenius, B., and Sandor, A. 1987. Vertical distribution of nematodes in arable soil under grass (Festuca pratensis) and barley (Hordeum distichum). Biol. Fertil. Soils 3:19-25.

Stamatakis, A., Hoover, P., and Rougemont, J. 2008. A rapid bootstrap algorithm for the RAxML web servers. Syst. Biol. 57:758-771.

Subbotin, S. A., Ragsdale, E. J., Mullens, T., Roberts, P. A., Mundo-Ocampo, M., and Baldwin, J. G. 2008. A phylogenetic framework for root lesion nematodes of the genus Pratylenchus (Nematoda): Evidence from $18 \mathrm{~S}$ and D2-D3 expansion segments of 28S ribosomal RNA genes and morphological characters. Mol. Phylogenet. Evol. 48:491-505.

Tarte, R., and Mai, W. F. 1976. Morphological variation in Pratylenchus penetrans. J. Nematol. 8:185-195.

Troccoli, A., Subbotin, S. A., Chitambar, J. J., Janssen, T., Waeyenberge, L., Stanley, J. D., Duncan, L. W., Agudelo, P., Uribe, G. E. M., and Franco, J. 2016. Characterisation of amphimictic and parthenogenetic populations of Pratylenchus bolivianus Corbett, 1983 (Nematoda: Pratylenchidae) and their phylogenetic relationships with closely related species. Nematology 18:651-678.

Vrain, T. C., Wakarchuk, D. A., Levesque, A. C., and Hamilton, R. I. 1992. Intraspecific rDNA restriction fragment length polymorphism in the Xiphinema americanum group. Fundam. Appl. Nematol. 15:563-573.

Waeyenberge, L., Ryss, A., Moens, M., Pinochet, J., and Vrain, T. C. 2000. Molecular characterisation of 18 Pratylenchus species using rDNA restriction fragment length polymorphism. Nematology 2:135-142.

Waeyenberge, L., Viaene, N., and Moens, M. 2009. Species-specific duplex PCR for the detection of Pratylenchus penetrans. Nematology 11:847-857.

Wang, H., Zhuo, K., Ye, W., and Liao, J. 2015. Morphological and molecular charaterisation of Pratylenchus parazeae n. sp.(Nematoda: Pratylenchidae) parasitizing sugarcane in China. Eur. J. Plant Pathol. 143:173-191.

Zhang, J., Kapli, P., Pavlidis, P., and Stamatakis, A. 2013. A general species delimitation method with applications to phylogenetic placements. Bioinformatics 29:2869-2876. 